\title{
Fabrication of Wireless Remote Controlled Electric Lawn Mower
}

\author{
Parthipan G, Dhiyaneswaran J, Vimal raja M, Rajesh K, Sanjeeviraj K
}

\begin{abstract}
Pollution is considered as an important problem in the present world. Usage of Gas Lawn-mowers creates Noise and Smoke pollution which is harmful to the environment. So the replacement of Gas mowers with the Electric lawn mowers which runs by Electric motors will be the better solution. The design objective is to build an electric lawn mower which is controlled by using a micro-controller called NodeMCU. The micro-controller is connected wirelessly to the mobile phone through Wi-Fi. The use of IoT (Internet of Things) in this lawn mower plays a major role. The whole model is controlled with the mobile application. We use a total of three controls in the application which is used to control the movements of the geared motors. Two of these controls are used for the motion of the lawn mower, and the third controls the cutting motor. The speed of all these motion motors can be controlled since analog outputs are obtained from the NodeMCU. Here, human effort is less. Compared to the gas mower, the electric mower has a less pollution rate.
\end{abstract}

Keywords: Lawn Mower, Electric Motors, Micro-controller, Node MCU

\section{INTRODUCTION}

Wireless technology has rapidly increased in the past years of the technological development. A lawn mower is a grass cutting machine with blades to cut the grass in an even height. The blades are powered by battery powered electric motor. A robotic lawn mower is designed in two ways. One is self-operated and the other one is remotely controlled by the human. The first lawn mower was designed by Edwin Budding in 1830 in Thrupp, just outside Stroud, in Gloucestershire, England. Budding's mower was designed mainly to cut the grass on sports grounds and extensive gardens, and he was granted a British patent on August 31, 1830. A rotary mower rotates about a vertical axis with the blade spinning at high speed depending on the impact to cut the grass. This leads to result in a rougher cut and shreds the grass leaf resulting in discoloration of the leaf ends as the tattered portion dies.

Manuscript published on 30 August 2019.

*Correspondence Author(s)

Parthipan G, UG Student, Department of Mechanical Engineering, Sri Krishna College of Engineering and Technology- Coimbatore, Tamil nadu-India- 641008

Dhiyaneswaran J, Assistant Professor, Department of Mechanical Engineering, Sri Krishna College of Engineering and TechnologyCoimbatore, Tamil nadu-India- 641008

Vimal raja M, Assistant Professor, Department of Mechanical Engineering, Kalaignar karunanidhi Institute of Technology, Coimbatore. Tamil nadu-India- 641402

K.Rajesh, Assistant Professor, Arunai engineering college Tiruvannamalai- Tamilnadu - India - 606603

K.Sanjeeviraj, Assistant Professor, Sreenivasa Institute of Technology and Management Studies, - Murukampattu- Chittoor- Andhra Pradesh- 517127.

(C) The Authors. Published by Blue Eyes Intelligence Engineering and Sciences Publication (BEIESP). This is an open access article under the CC-BY-NC-ND license http://creativecommons.org/licenses/by-nc-nd/4.0/
Electric mowers are the grass cutting machines runs by electric motors. The noise rate produced by the Electric mower is less than 75 decibels, while a gas lawn mower produces about 95 decibels of noise rate. Corded electric mowers are nothing but the mower which gets the power through limited range wires from the nearest available power outlet.

The extending range may differ from 35 to $40 \mathrm{~m}$ at maximum level. Cordless electric mowers are wireless, means the mowers are powered by variable 12 volt, 56 volt and 80 volt batteries. The run time of the mower increases with the increase in the capacity of the battery. Batteries can be placed either inside or outside of the lawn mower. If on the outside, the depleted batteries can be quickly swapped with recharged batteries. A recent study assessed the occupational noise exposure among groundskeepers at several North Carolina public universities and found noise levels from push lawn mowers measured between 86-95 decibels (A-weighted) and from riding lawn mowers between 88 and $96 \mathrm{~dB}(\mathrm{~A})$; both types exceeded the National Institute for Occupational Safety and Health (NIOSH) Recommended Exposure Limit of $85 \mathrm{~dB}(\mathrm{~A})$. To reduce the possibility of developing hearing loss and reduce noise pollution, users might consider the use of reel mowers or newer "green" or battery-operated mowers.

\section{METHODOLOGY}

\section{A. Figures}

The methodology is to fabricate a lawn mower which is remotely controlled. The design methodology for the mechanical aspects of the project was to design the lawn mower in section such as mechanical section and the electrical section. After the finalization of the frame design the model was begun for the fabrication. Before the start of the construction part the frame design was first completed in CREO. The frame design made according to the requirements like electrical housing, wheel mounting and the housing of the cutter blades. After the construction of the frame, the electrical design process was started. The process began with the choosing of the electrical components needed for the mower.

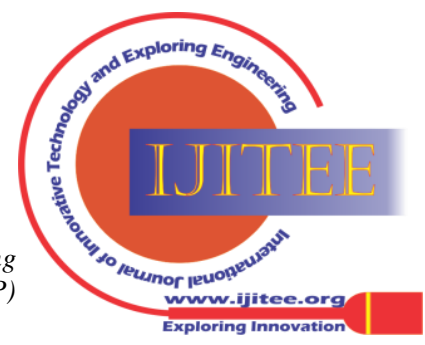




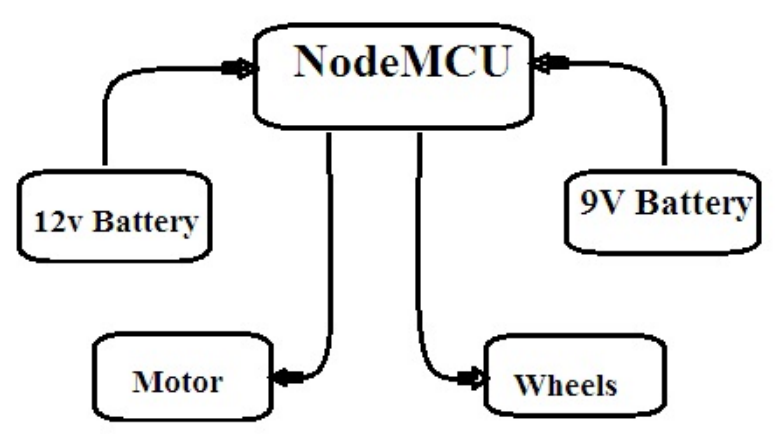

Figure 1 Methodology

The figure 1 shows the methodology of the electrical connections of the mower. Circuit diagrams were drawn to show the electrical connections programs were written for the controls. It was necessary to make sure the communication and the controls were working properly. Finally, the construction part of the mower was completed.

\section{OBJECTIVE}

Our main objective was to create a grass cutting vehicle which runs through electric motor and planned the usage of sufficient batteries for the power supply. We planned to reduce the manpower so, we tried installing a microcontroller through which we can control the vehicle through the mobile phone. The size of the mower is simple and compact. The weight is also comparatively much lower than the gas lawn mower.

\section{COMPONENTS USED}

BATTERY: This is a main component which powers the electric motors and the micro-controller. So, $12 \mathrm{v}$ battery is chosen as the power supply for the DC motors and $9 \mathrm{v}$ battery to power the micro-controller.

FRAME: A Wooden material is chosen for the frame of the mower. So the weight of the mower becomes less and it will be reliable.

MICRO-CONTROLLER: NodeMCU was the micro-controller used in the model. It is a open-source, interactive, programmable, low cost, simple, smart, WI-FI enabled. Since, it is embedded with the WI-FI, it can be connected to the mobile phone.

CUTTING MOTOR: A $12 \mathrm{v}$ DC motor was used as a cutting motor which has the speed of about 1800rpm. Battery was chosen according to the motor's specification.

GEARED MOTOR: Two side-shaft geared motors were used for the movement of the wheels. The torque will be high in the side-shaft motor. $12 \mathrm{v}$ DC battery was used to power up these motors.

WHEELS: Four wheels were used in this model. Two were rotating caster wheels and the other two were the Robot wheels. The robot wheels were fixed to the Side-shaft motors. These were responsible for the movement of the mower.

BREAD BOARD: Usage of the bread board in this model makes the electrical circuit connection easier. It's a type of solderless electronic circuit building.

L-CLAMP (GEAR MOTOR): This motor mount bracket is designed for the side-shaft series and side shaft HP series motor, making motor mounting convenient.

The below displayed figure 2 shows the isometric view of frame of the lawn mower model which was designed using the software called CREO.The design of the mower was planned to compact and with lesser weight.

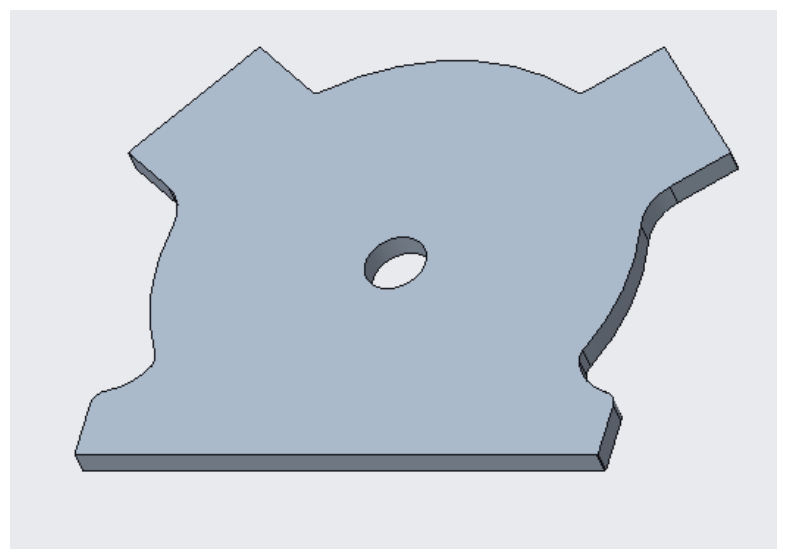

Figure 2. Isometric view of the model

Figure 3 Isometric view of the caster wheel

The above figure 3 shows the isometric view of the caster wheel. The main reason for choosing this caster wheel is because it has the 360 degree rotating capability.

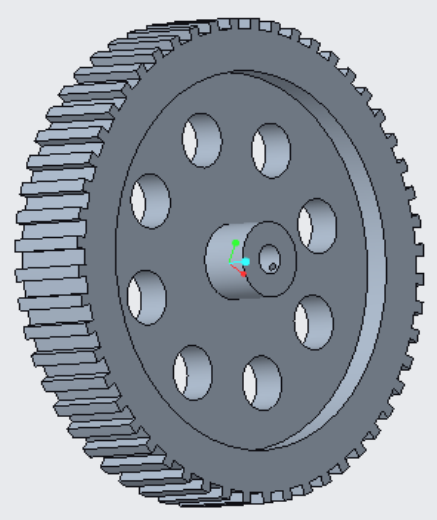

Figure 4 Isometric view of the Robot wheel The above figure 4 shows the isometric view of the robot wheel. This wheel is fitted with the side shaft motor.

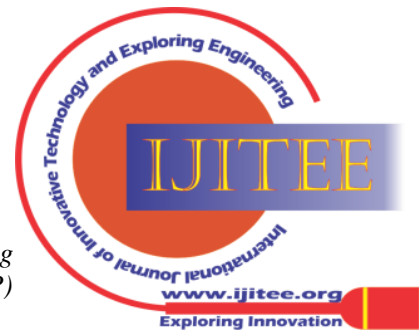




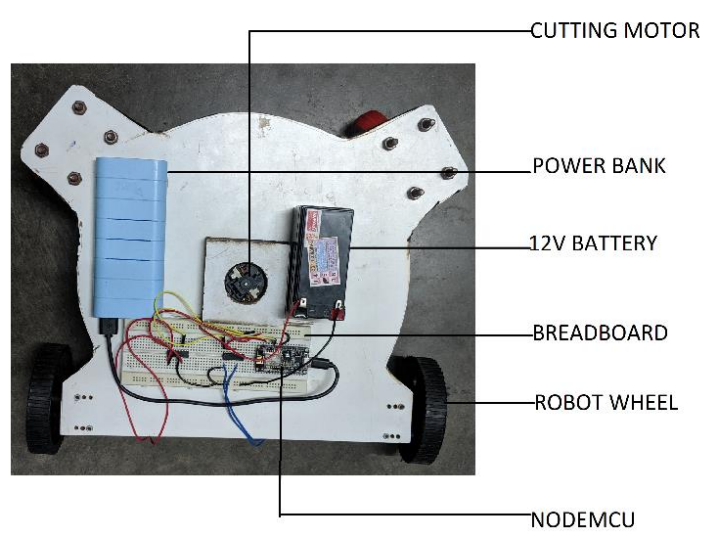

Figure 5 Top view

The above figure 5 shows the top view of the complete model with the electrical connections in it. The electric motor is mounted at the center for the better convenience

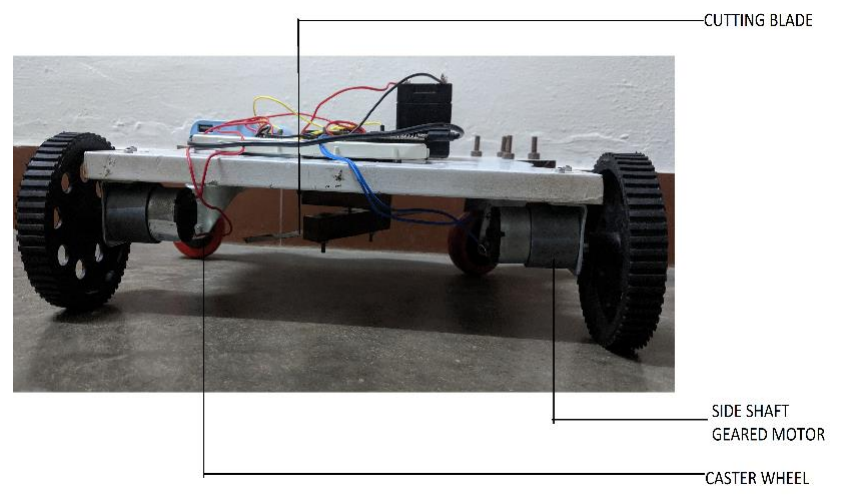

Figure 6 Front view

The above figure 6 shows the front view of the complete model with the part name marked on it.

\section{WORKING}

\section{ELECTRICAL WORKING:}

The remote control lawn mower is controlled via a $\mathrm{Wi}-\mathrm{Fi}$ module named ESP8266, NodeMCU. A NodeMCU is a micro controller, which has a firmware and a built-in Wi-Fi. Using IDE, such as Arduino IDE, a program is compiled and uploaded to the board. The program contains instructions such as the Wi-Fi network it has to connect and authentication token for proper usage. When the NodeMCU is powered, (9V in our case), it connects to the Wi-Fi network given to it whenever the network is available and within the range. Using appropriate application, we can control the output pins of the NodeMCU. For each instruction given in the app, the instruction is uploaded to a server given in the program, and the server in turn gives instruction to the NodeMCU, which controls the output pins.

When a forward movement is given in the application and with its pin information, the NodeMCU's specified output pin produces $3.3 \mathrm{~V}$. This voltage is not suitable for direct application to the motor, because $3.3 \mathrm{~V}$ cannot control a $12 \mathrm{~V}$ motor. This is overcome by a relay driver microcontroller IC named "ULN2003A". The output of the NodeMCU is given to the input of the ULN2003A IC. The output of the IC is then given to the motor. The ULN2003A IC consists of Darlington transistor pair, which amplifies the input signal. So that the output signal is multiplied and given to the required actuators (Motors). The ULN is powered by $12 \mathrm{~V}$ power supply, so that the maximum output voltage is $12 \mathrm{~V}$, which is suitable for the actuator used here.

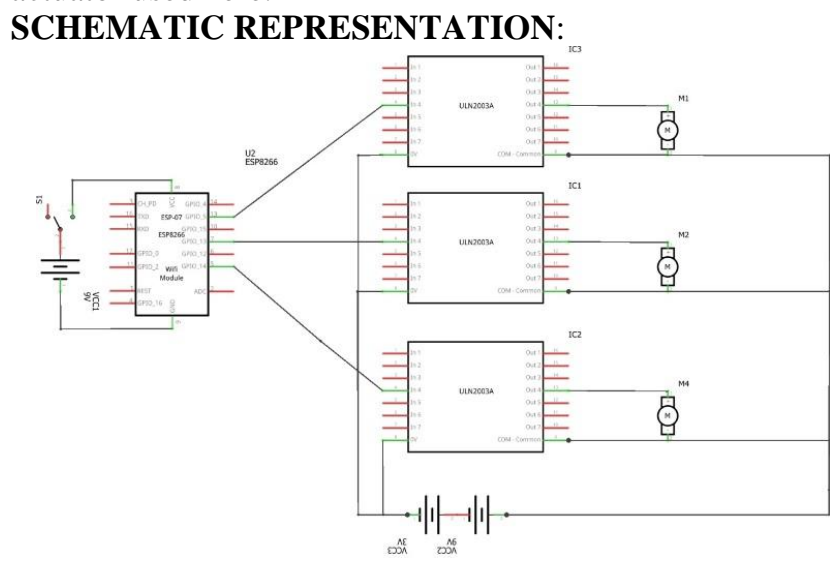

Figure 7 Schematic representation of the Electrical circuit connection

The above figure 7 shows the schematic representation of the Electrical circuit connection of the model.

\section{WORKING OF THE MODEL:}

The whole model is controlled with the mobile application. We use a total of three controls in the application which is used to control the movements of the geared motors. Two of these controls are used for the motion of the lawn mower, and the third controls the cutting motor. The speed of all these motion motors can be controlled, since analog outputs are obtained from the NodeMCU. The analog value ranges from 0 to 1023 , where 0 represents the off state and 1023 represents the on state when mapped into digital form. The values between the states are analog, and so the speed of the motor can be controlled. When both the motion motors are given analog value of 1023 from the control slider used in the application, the lawn mower starts moving forward. When the left motor is given less value, the speed of the left motor decreases, and since the right motor is intact with 1023 analog value, the lawn mower moves towards left direction. And likewise, the lawn mower moves towards right, when the right motor is given low analog value, when the left is kept at 1023. The cutting motor's speed can be provided with analog values if one intents to, but there won't be necessary for the cutting motor to be slow in our case. Hence digital control can be used to turn on and turn off the cutting motor.

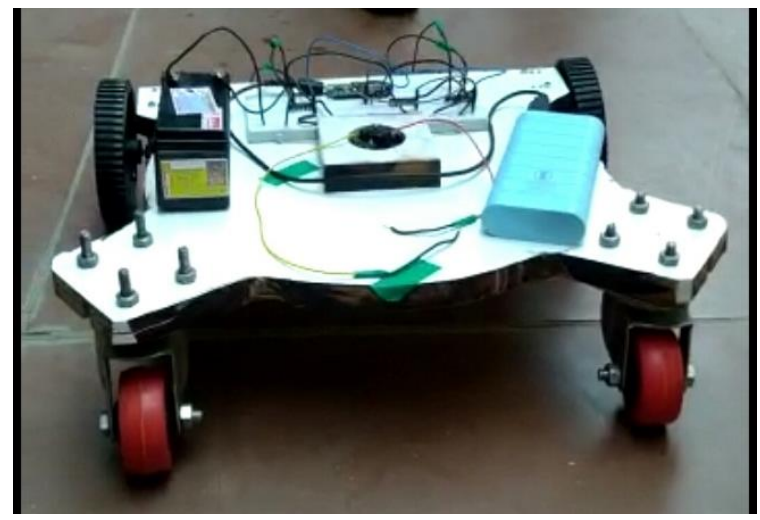

Figure 8 Working of the Electric Lawn mower

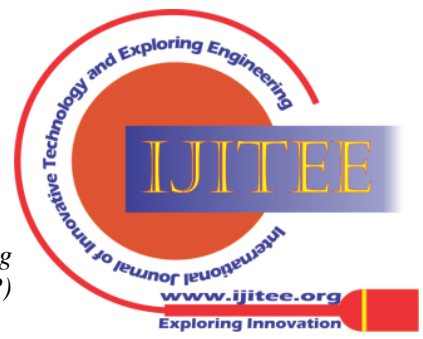




\section{DESIGN CALCULATION}

TORQUE PRODUCED THE CUTTING MOTOR:

Motor type: DC motor

Speed $=1800 \mathrm{rpm}$

Voltage $=12$ volt

Power $=180$ watt

$$
\begin{aligned}
\mathrm{T} & =(\mathrm{p} \times 60) /(2 \times \pi \times \mathrm{N}) \\
& =(180 \times 60) /(2 \times \pi \times 1800) \\
\mathrm{T} & =0.955 \mathrm{~N}
\end{aligned}
$$

Hence, the torque produced by the cutting motor is $0.955 \mathrm{~N}$.

\section{CONCLUSION}

Usage of electric lawn mower reduces smoke and noise pollution. Our lawn mower is light in weight when compared to the gas lawn mowers. Here, since we used the micro-controller by which we can control the lawn mower from our mobile using the Wi-Fi connection. The usage of this micro-controller reduces the labour work. We've built a smaller but efficient one .For the heavy processes we can built a bigger one with the usage of heavy electric motors.

\section{REFERENCE}

1. Priest, M. W., D. J. Williams, and H. A. Bridgman. "Emissions from in-use lawn-mowers in Australia." Atmospheric Environment 34.4 (2000): 657-664.

2. Lerman, Susannah B., and Alexandra R. Contosta. "Lawn mowing frequency and its effects on biogenic and anthropogenic carbon dioxide emissions." Landscape and urban planning 182 (2019): 114-123.

3. Simple Design of Self-Powered Lawn Mower, Basil Okafor , Department of Mechanical Engineering, Federal. University of Technology Owerri, Imo State, Nigeria

4. Optimization of the operating parameters of a grass trimming machine, Zulquernain Mallick*, Department of Mechanical Engineering, Jamia Millia Islamia, Jamia Nagar, New-Delhi-110025, India

5. "Arduino Alternatives: 5 Microcontrollers You Should Know." Popular Mechanics.

6. "RCArduino" How To Read an RC Receiver With A Microcontroller.

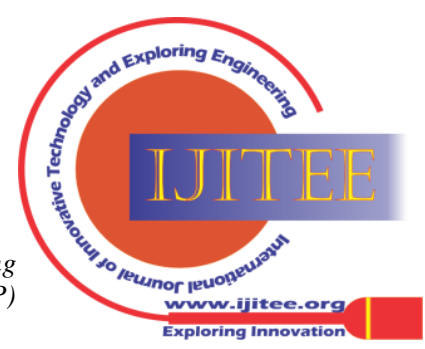

